\title{
Research on vibration reduction of multiple parallel gear shafts with ISFD
}

\author{
Kaihua Lu${ }^{1}$, Lidong He${ }^{2}$, Wei Yan ${ }^{3}$ \\ Beijing Key Laboratory of Health Monitoring and Self-Recovery for High-End Mechanical Equipment, \\ Beijing University of Chemical Technology, Beijing, 100029, China \\ ${ }^{2}$ Corresponding author \\ E-mail: ${ }^{1}$ kaihualu1991@163.com, ${ }^{2} 1963 h e @ 163 . c o m,{ }^{3}$ yanwei0416@126.com
}

Received 4 October 2018; accepted 9 October 2018

DOI https://doi.org/10.21595/vp.2018.20303

Check for updates

Copyright $(2018$ Kaihua Lu, et al. This is an open access article distributed under the Creative Commons Attribution License, which permits unrestricted use, distribution, and reproduction in any medium, provided the original work is properly cited.

\begin{abstract}
The vibration reduction methods for reducing the complexly coupled vibrations in multiple parallel gear shafts using integral squeeze film damper (ISFD) is studied in this paper. A multiple parallel gear system with three involute spur gears is built, and experiments are carried out to compare the vibrational characteristics of the gear system with rigid support and ISFD elastic damping support. The experimental results show that the ISFD support can reduce the shock vibrations of the multiple parallel gear shafts with excellent vibration attenuation characteristics due to damping. ISFD elastic damping support can inhibit the vibrations in a wide frequency range during the gear transmission, which can guarantee a smooth transition between multiple parallel gear shafts over a range of operating speeds.
\end{abstract}

Keywords: multiple parallel gear shafts, integral squeeze film damper (ISFD), elastic damping support, vibration reduction.

\section{Introduction}

During the gear transmissions, the system will vibrate because of the factors such as manufacturing errors, installation errors and harsh working conditions. The vibrations in the gear system will not only produce a large noise but also accelerate the fatigue damage of the equipment, deteriorating the working environment [1]. The multiple gear shafts are a typical form of the gear transmission, with a common application of integral gear assembly centrifugal compressor. Due to the coupling between multiple gears, the vibration of each shaft is no longer to be independent of each other [2]. Moreover, the dynamic performance of the multiple gear shafts system is different from that of the common first-grade gear transmission system. The structure of the multiple gear shafts is quite complex, with harsh operating conditions and prone to faults. The vibrations caused by the shaft faults will cause the other rotating shafts to vibrate due to the coupling between the gears. Long term vibrations will cause damage to the equipment.

For the safe and efficient operation of rotating machinery, the vibration suppression in a rotor system is very important. Increasing the damping in the supporting system is a common technique for reducing the vibration of the rotor [3]. Squeeze film damper (SFD) has been used for decades in turbomachinery such as aircraft engines [4]. The improved integral squeeze film damper (ISFD) adds viscous damping to the mechanical system, reducing the amplitude of lateral vibration of the rotor bearing and isolating the vibrations transmitted to other structural components [5]. Because of its special structural form, the problem of nonlinear oil film existing in traditional SFD can be resolved [6]. ISFD has been applied in turbomachines such as compressors and engines to reduce the vibration of rotors at critical speeds and improve the stability of rotor systems.

Due to the complex dynamic characteristics of multiple parallel gear shafts, the ISFD is considered to control its complex vibrations. Based on the multiple parallel gear shafts structure of integral gear assembly centrifugal compressor, a multiple parallel gear shafts test rig is set up. By comparing the vibrations of the gear shaft equipped with rigid support and ISFD elastic damping support, the vibration reduction characteristics of ISFD for multiple parallel gear shafts are studied. 


\section{Integral squeeze film damper}

\subsection{Structural features of ISFD}

ISFD is a bearing damper, made via wire cutting and manufacturing. The ISFD structure for the experiment is shown in Fig. 1. The inner and outer damper flanges are divided by the ring, acting as a squeeze film area. The gap is $0.2 \mathrm{~mm}$, and the fluid squeezed into this gap will provide viscous damping for the rotor system. The S-shaped spring divides the circumferential film area into a plurality of local sections. It prevents the circumferential circulation of the oil, thus, reducing the nonlinear influence of the oil film [7]. The uniformly distributed S-shaped spring determines the radial stiffness of the supporting system. It can effectively absorb the shock energy and improves the stability of the system. The ISFD is generally used in series with different types of bearings to form the support structure of the rotor. Fig. 2 shows the ISFD structure with a ball bearing.

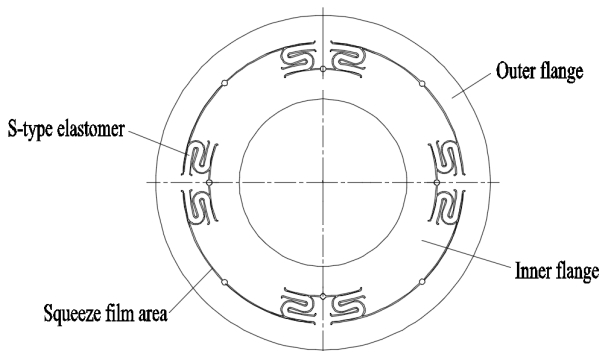

Fig. 1. Integral squeeze film damper

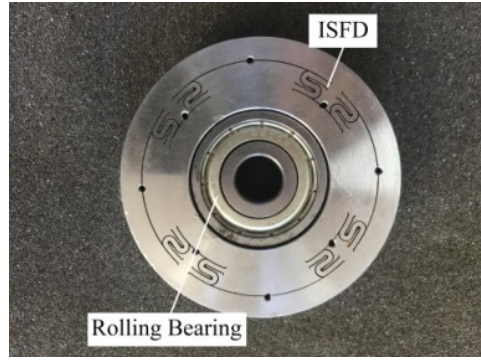

Fig. 2. ISFD with ball bearing

\subsection{Mechanical model of ISFD}

To analyze the influence of introducing the ISFD on the mechanical properties of the bearing system, the mechanical models of the rigid bearing support system and the bearing support system with ISFD are listed in Fig. 3.

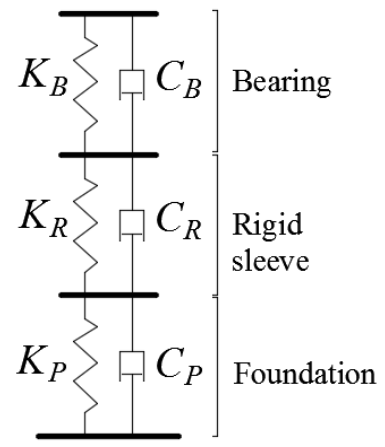

a) Rigid bearing support

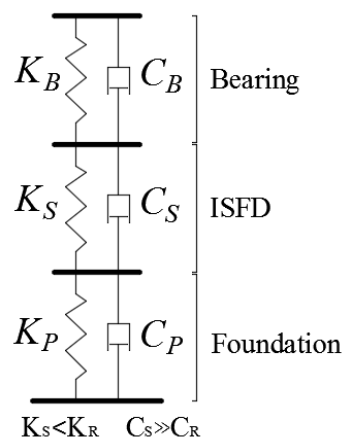

b) ISFD bearing support

Fig. 3. Mechanical models of rigid bearing support system and ISFD bearing support system

It can be seen from this model that by introducing the ISFD structure in the system, several orders of reduction of the stiffness of the bearing system is achieved. The lower bearing support stiffness relieves the vibration impact during the transmission process and absorbs a certain amount of vibration energy. Also, the viscous damping provided by the ISFD can dissipate the vibration energy and improves the damping ratio of the rotor system. 


\section{Experimental setup}

\subsection{Types of supporting structures}

Two supporting structures were designed based on the test bench: rigid supports and ISFD elastic damping supports, as shown in Fig. 4. The rigid support consists of bearing block, rigid sleeve and rolling bearing. The ISFD elastic damping support consists of bearing block, S-type elastomer, a rolling bearing and sealing structure. The sealing structure is mainly composed of an end cover and O-type rubber ring. During the experiment, the damping fluid is added through the grease hole.

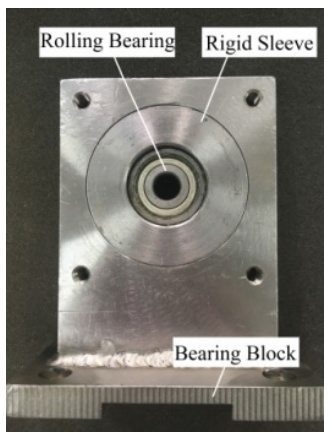

a) Rigid support structure

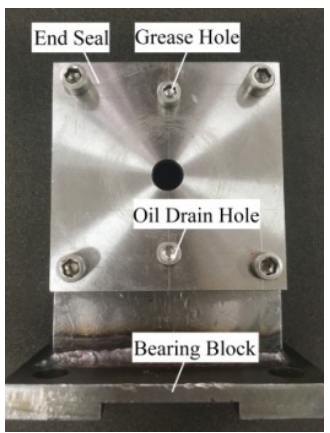

b) ISFD elastic damping support structure

Fig. 4. Two types of support structures

\subsection{Multiple parallel gear shafts test rig}

The structure of integral gear assembly centrifugal compressor, and multiple parallel gear shafts test rig is shown in Fig. 5.

A permanent magnet DC servomotor drives the transmission system with an output speed range of 0-10000 r/min. During the experiment, the dripping method is used to lubricate the gear pair.

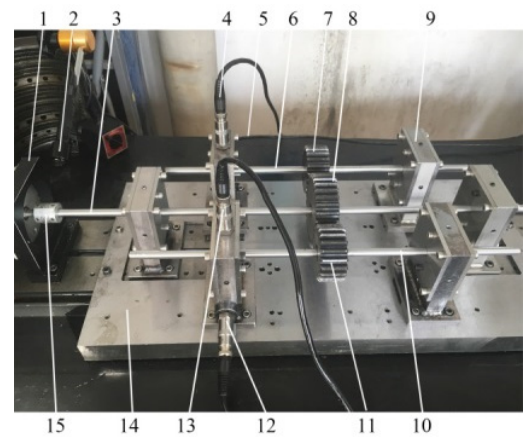

Fig. 5. Multiple parallel gear shafts test rig: 1 - motor, 2 - photoelectric sensor, 3 - drive shaft, 4 -acceleration sensor 1,5-acceleration sensor 2,6-driven shaft 2, 7 -driven gear 2, 8 - drive gear, 9 - ISFD elastic damping support, 10 - driven shaft 1, 11 - driven gear 1 , 12 - acceleration sensor 3,13 -acceleration sensor 4, 14 - base plate, 15 - coupling

\subsection{Data acquisition settings}

The LC-8008 vibration monitoring and diagnosis system (as shown in Fig. 6) is used for vibration test in the experiment. During the experiment, the analyzed frequency is determined as $2 \mathrm{kHz}$ with 1024 sampling points. 
The vibration is measured using the acceleration sensors adsorbed on the bearing block, and the peaks of the vibration acceleration along the horizontal and vertical directions of the two driven shaft's bearing blocks are measured. The photoelectric sensor is used to measure the rotational speed.

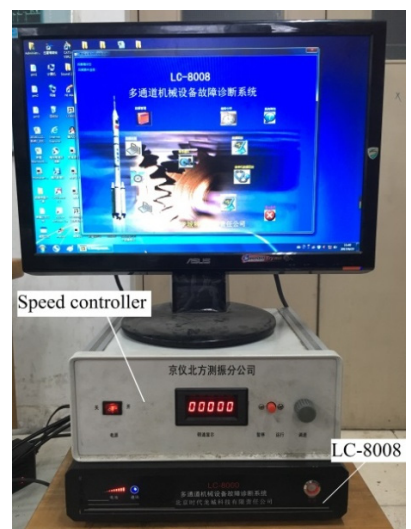

Fig. 6. Data acquisition system LC-8008

\section{Experimental results and discussion}

\subsection{Study on vibration suppression of multiple parallel gear shafts with ISFD}

The output speed of the drive shaft is $n_{1}=1200 \mathrm{r} / \mathrm{min}$ ( $\pm 5 \mathrm{r} / \mathrm{min}$ fluctuation), then the speed of two driven shafts is $n_{2}=n_{1} * i=1800 \mathrm{r} / \mathrm{min}$. Meshing frequency of the gear pair is $f=f_{1} Z_{1}=f_{2} Z_{2}=600 \mathrm{~Hz}$. Table 1 shows the peak of the vibration acceleration at the measuring point when the gear shaft is installed with rigid support and ISFD elastic damping support.

It can be seen from Table 1. that the peak of the vibration acceleration at each measuring point is reduced after the rigid support is replaced with the ISFD elastic damping support. Considering the horizontal vibration data at the measuring point of driven shaft 1 as an example, when the gear system is changed from the rigid support to ISFD support, the peak of the vibration acceleration is reduced from $4.03 \mathrm{~m} / \mathrm{s}^{2}$ to $2.59 \mathrm{~m} / \mathrm{s}^{2}$, with a reduction of $35.7 \%$. The time and frequency domains acceleration data of the two kinds of supporting conditions are extracted, and the vibration control effect of ISFD elastic damping support on multiple parallel gear shafts is analyzed. The acceleration time domain waveform is shown in Fig. 7, and Fig. 8 provides a comparison of the acceleration spectrum.

Table 1. Vibration amplitude of the bearing block

\begin{tabular}{|c|c|c|c|c|}
\hline \multirow{2}{*}{ Vibration amplitude $\left(\mathrm{m} / \mathrm{s}^{2}\right)$} & \multicolumn{2}{|c|}{ Driven shaft 1 } & \multicolumn{2}{c|}{ Driven shaft 2 } \\
\cline { 2 - 5 } & Horizontal & Vertical & Horizontal & Vertical \\
\hline Rigid support & 4.03 & 6.48 & 6.27 & 7.03 \\
\hline ISFD support & 2.59 & 4.56 & 4.08 & 4.10 \\
\hline Decrease (\%) & 35.7 & 29.6 & 34.9 & 41.7 \\
\hline
\end{tabular}

From the time domain waveform shown in Fig. 7, there is a shock vibration in the gear meshing transmission. The shock vibration may be caused either by the load fluctuation or due to the poor gear installation. Comparing the rigid support and the ISFD support cases, it can be seen clearly from the diagram that the modulation phenomenon has been improved in ISFD support case, and the impact vibration has been reduced. Also, it can be seen from Fig. 8 that the amplitude of vibration at meshing frequency is relatively large with a wide sideband. Additionally, the large vibration value occurs near $100 \mathrm{~Hz}$ and $740 \mathrm{~Hz}$. According to the vibration theory [10], there is a resonance modulation phenomenon. After using ISFD, the vibrations at the three frequencies are 
greatly reduced, and the resonance modulation of the gear shaft is improved to a greater extent. This shows that the ISFD elastic damping support has excellent damping performance with a better vibration suppression effect on the vibration in a wide frequency band.

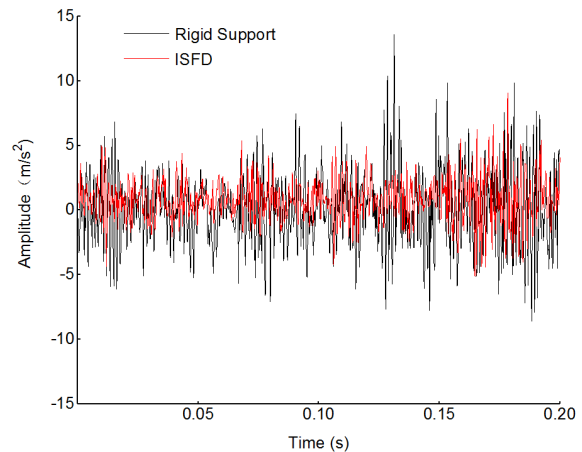

Fig. 7. Comparison of time domain waveform

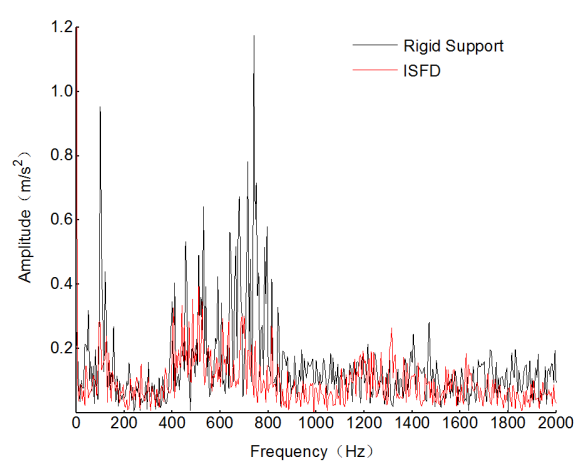

Fig. 8. Comparison of the frequency spectrum

\subsection{Vibration analysis at different rotational speeds}

To further study the ISFD elastic damping system's effect on the vibrations of the multiple parallel gear shafts, the vibration characteristics of the gear systems at different speeds are experimentally studied. The input speeds of the drive shaft are set to $900 \mathrm{r} / \mathrm{min}, 1200 \mathrm{r} / \mathrm{min}$, and $1500 \mathrm{r} / \mathrm{min}$, then the speeds of two driven shafts are $1350 \mathrm{r} / \mathrm{min}, 1800 \mathrm{r} / \mathrm{min}$, and $2250 \mathrm{r} / \mathrm{min}$.

The vibration of the bearing block is measured with the two supporting structures, and the peak of the acceleration at each measuring point at different rotational speeds is obtained. The vibrations of the measuring points of the driven shaft 1 and the driven shaft 2 are shown in Fig. 9, 10.

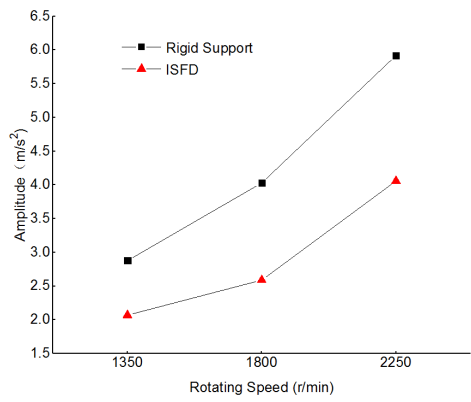

a) Horizontal measuring point

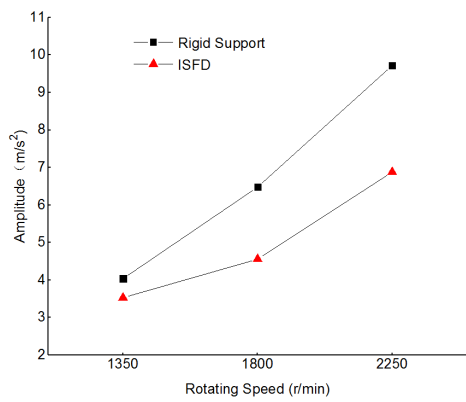

b) Vertical measuring point

Fig. 9. Comparison of vibration of driven shaft 1 measuring points

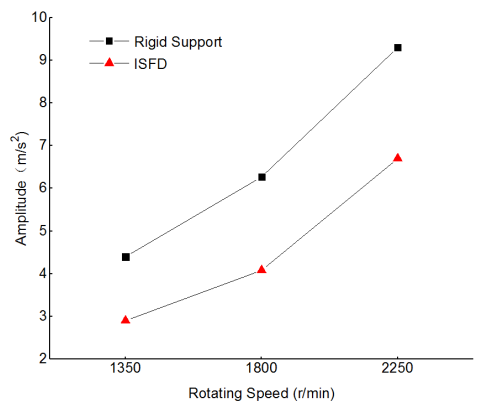

a) Horizontal measuring point

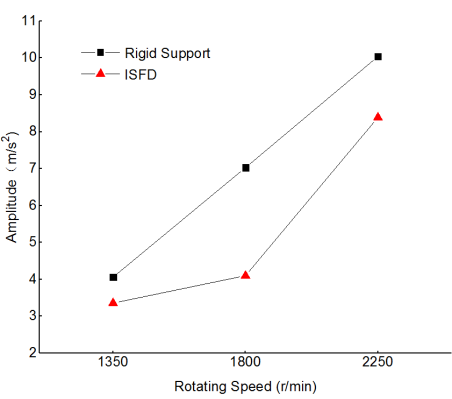

b) Vertical measuring point

Fig. 10. Comparison of vibration of driven shaft 2 measuring points 
As shown in Fig. 9 and 10, the vibration of the gear shaft increases with an increase of the rotational speed. From the rigid support to the ISFD elastic damping support, the vibration amplitudes of the measuring points are greatly reduced. The experimental results show that the ISFD elastic damping support can make the multiple parallel gear shafts operate smoothly in a wide speed range.

\section{Conclusions}

1) The ISFD elastic damping support can reduce the shock vibration of the multiple parallel gear shafts with excellent damping vibration attenuation characteristics.

2) The ISFD elastic damping support has a better suppression effect on the vibration at a wide frequency band in gear transmission.

3) The ISFD elastic damping support can make the parallel gear shafts operate smoothly in a wide speed range.

\section{Acknowledgements}

This work is supported by the National Basic Research Program of China (2012CB026000) and Key Laboratory Fund for Ship Vibration and Noise (614220406020717).

\section{References}

[1] Xiao W. Q., Huang Y. X., Li W., et al. Influence of particle damper configurations on the dynamic characteristic for gear transmission system. Journal of Mechanical Engineering, Vol. 53, Issue 7, 2017, p. 1-12.

[2] Xia B. Q., Yu L., Xie Y. B. Dynamics analysis of geared rotor-bearing system of DH type turbine compressor. Journal of Vibration Engineering, Vol. 16, Issue 2, 2003, p. 251-255.

[3] Xing J., He L. D., Wang K. Optimizing control for rotor vibration with magnetorheological fluid damper. Transactions of Nanjing University of Aeronautics and Astronautics, Vol. 31, Issue 5, 2014, p. 538-545.

[4] Andrés L. S., Lubell D. Imbalance response of a test rotor supported on squeeze film dampers. Journal of Engineering for Gas Turbines and Power, Vol. 120, Issue 2, 1997, p. 1163-1164.

[5] Ertas B., Delgado A., Moore J. Dynamic characterization of an integral squeeze film bearing support damper for a supercritical $\mathrm{CO} 2$ expander. Proceedings of ASME Turbo Expo: Turbomachinery Technical Conference and Exposition, Charlotte, NC, USA, 2017.

[6] Ertas B., Cerny V., Kim J., et al. Stabilizing a 46 MW multi-stage utility steam turbine using integral squeeze film bearing support dampers. Proceedings of ASME Turbo Expo: Turbomachinery Technical Conference and Exposition, Düsseldorf, Germany, 2014.

[7] Santiago O. D., Andrés L. S., Oliveras J. Imbalance response of a rotor supported on open-ends integral squeeze film dampers. Journal of Engineering for Gas Turbines and Power, Vol. 121, Issue 4, 1998, p. 718-724.

[8] Wang G. Z., Sun P. L., Fang K. X. A research on the reduction of vibration and noise of the gearbox by using damping alloys. Journal of Jiangsu University of Science and Technology (Natural Science Edition), Vol. 8, Issue 3, 1994, p. 14-20.

[9] Zhu S. J., Lou J. J., He Q. W., et al. Vibration Theory and Vibration Isolation. First Edition, National Defense Industry Press, Beijing, 2006.

[10] Ding K., Li W. H., Zhu X. Y. Gears and Gearbox Fault Diagnosis Practical Technology. First Edition, Machinery Industry Press, Beijing, 2005. 